\title{
Simulation of Velocities in the Yucatan Channel*
}

\author{
T. Ezer, L.-Y. Oey and H.-C. Lee \\ Princeton University, Program in Atmospheric \& Oceanic Sciences \\ Princeton, NJ, 08544-0710, USA \\ ezer@splash.princeton.edu
}

\begin{abstract}
As part of the analysis of results from high resolution numerical simulations of the Gulf of Mexico and the Caribbean Sea, the structure and variability of the flow across the Yucatan Channel are described and compared with observations. The main model inflow into the Gulf is found near the surface in the western part of the Channel, while return flows back into the Caribbean Sea are found near the surface on the eastern side of the Channel and along the eastern and western slopes around $1500 \mathrm{~m}$ depth, in agreement with recent observations. Variations in the upper inflow and deep outflow transports seem to correlate with variations in the extension of the Loop Current, as suggested by previous analyses of observations and models. Such correlations are especially high near the time when Loop Current eddies are shed into the Gulf of Mexico.
\end{abstract}

\section{INTRODUCTION}

Despite the importance of the Yucatan Channel (YC) flow as the sole passage of water from the Caribbean Sea (CS) into the Gulf of Mexico (GOM), Fig. 1., our knowledge of the structure and variability of the Channel's flow was limited in the past due to limited direct measurements in the Channel (e.g., [1]). However, recent observations, ([2], [3]), show a considerably more complex flow field than previously thought, and suggest that the mean Channel transport $(\sim 24$ $\left.\mathrm{Sv} ; 1 \mathrm{~Sv}=10^{6} \mathrm{~m}^{3} \mathrm{~s}^{-1}\right)$ is smaller than previous estimates $(28-30$ Sv; [4]). The new observations also allow a more detailed evaluation of model results than previously was possible.

Excess inflow transport into the GOM through the deep $(\sim 2000 \mathrm{~m})$ YC, relative to the outflow through the shallower $(\sim 800 \mathrm{~m})$ Florida Straits (FS) may lead to increase in the northward extension of the Loop Current (LC). Consequently, the excess inflow is returned as a deep outflow in the YC. An early attempt by [1] to find a correlation between the observed deep flow over the center of the YC sill and variations in the LC was unsuccessful. However, the more recent observations in [3] show a significant correlation between the deep flow and the LC extension, but they also indicate that the deep return flows are found along the side slopes of the Channel and not at the center of the sill where the current meter in [1] was located.

Results from a realistic numerical ocean model are analyzed in order to investigate the spatial structure of the flow across the YC and compare them with some of the new published observations. The relation between the transport across the $\mathrm{YC}$ and variations in the LC extension (and possibly LC eddy shedding events) are also investigated.

"Supported by the Mineral Management Service (MMS) and the Office of Naval Research (ONR).

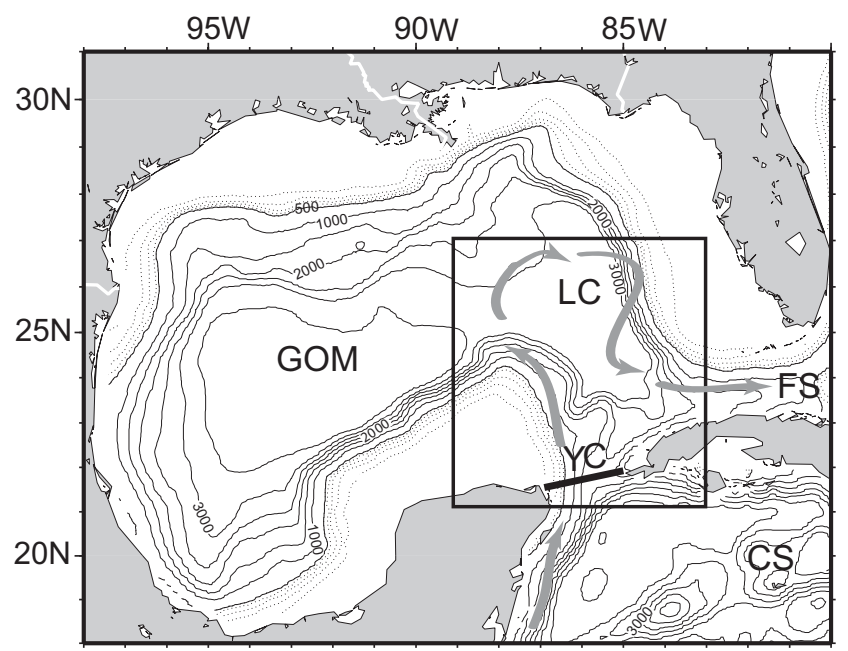

Fig. 1. Bottom topography and main features of the study area (the model domain is larger than the shown area, see section II). The Caribbean Sea (CS), the Gulf of Mexico (GOM), the Loop Current (LC), the Florida Straits (FS) and the Yucatan Channel (YC) are indicated. The model cross section of Fig. 2 is marked by the solid line. The box around the LC indicates the area in which sea surface height was averaged in order to estimate the LC extension area.

\section{MODEL DESCRIPTION}

The model is based on the three-dimensional, sigmacoordinate, primitive equation, Princeton Ocean Model (POM, [5]). The model domain is $55^{\circ} \mathrm{W}-99^{\circ} \mathrm{W}$ and $5^{\circ} \mathrm{N}-$ $55^{\circ} \mathrm{N}$, so that the Gulf Stream, the Gulf of Mexico and the Caribbean Sea are included as described in [6] and [7]. Unlike some GOM models with boundary conditions imposed at the YC itself or in the western Caribbean Sea ([8], [9]), here a larger domain is used, so that the dynamics of the $\mathrm{YC}$ is less affected by the boundary conditions. As shown in [10] and in other basin-scale modeling studies, westward propagating eddies in the Caribbean Sea may affect the dynamics of the YC. Horizontal resolution of the curvilinear orthogonal grid is between 5 and $10 \mathrm{~km}$ in the GOM. There are 25 vertical sigma levels, with higher resolution near the surface and near the bottom. Surface forcing includes wind stress in 6-hour intervals obtained from the European Center for Medium range Weather Forecast (ECMWF) and surface heat flux and buoyancy forcing based on monthly climatology. This study analyzes the wind-driven model for 1993 through 1996. More details about the model setting, analyses of deep and coastal processes, and the effect of data assimilation (not included here) are found in [6], [7], [11] and [12]. Here we only focus on one aspect of the model resultsthe structure of the flow in the Yucatan Channel. 


\section{MODEL RESULTS}

\section{A. The Spatial Structure of the Flow Field}

We first look at the spatial structure of the along-channel mean velocity, obtained from the four-year simulation, and shown in the center of Fig. 2. There are in the model several cores of local maxima in flow speed, in locations similar to those found in the observations reported in [2] and [3]. The inflow into the Gulf is found near the surface on the western (Mexican) side of the Channel and has a maximum mean velocity of $1.48 \mathrm{~m} \mathrm{~s}^{-1}$ (Fig. 2a). A return outflow on the upper-eastern (Cuban) side of the Channel has a maximum mean flow of $-0.25 \mathrm{~m} \mathrm{~s}^{-1}$; this feature is also found in observations ([2], [3]), but the observations show weaker mean velocities there. Both, the model and the observations, show that the deep return flows are found along the slopes of the Channel and not at the center as previously expected. The deep outflow on the western side of the Channel at $1300 \mathrm{~m}$ depth, with a maximum mean velocity of $-0.17 \mathrm{~m} \mathrm{~s}^{-1}$ (Fig. $2 \mathrm{c}$ ), is always southward, while the outflow on the eastern side of the Channel at $1400 \mathrm{~m}$ depth, with a maximum mean velocity of $-0.09 \mathrm{~m} \mathrm{~s}^{-1}$ (Fig. 2d), is occasionally reversed in direction due to meandering of the upper inflow (see [12]). (a)

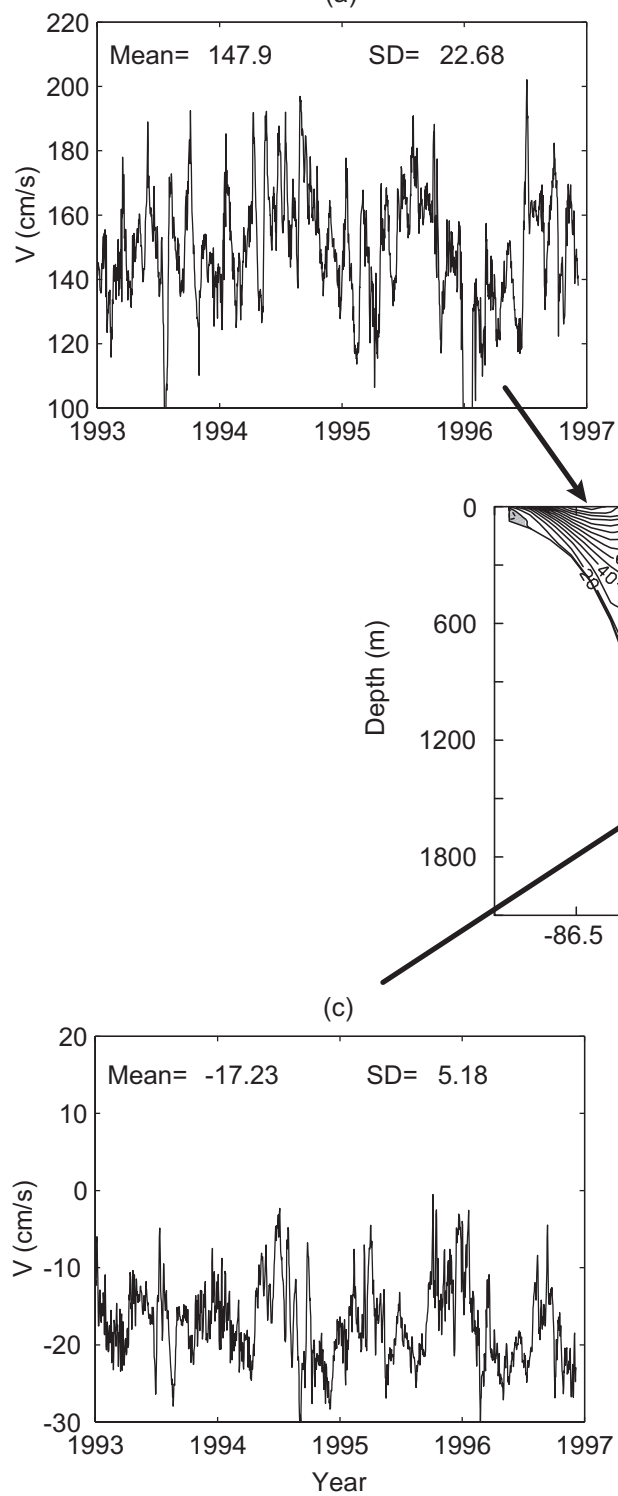

(b)

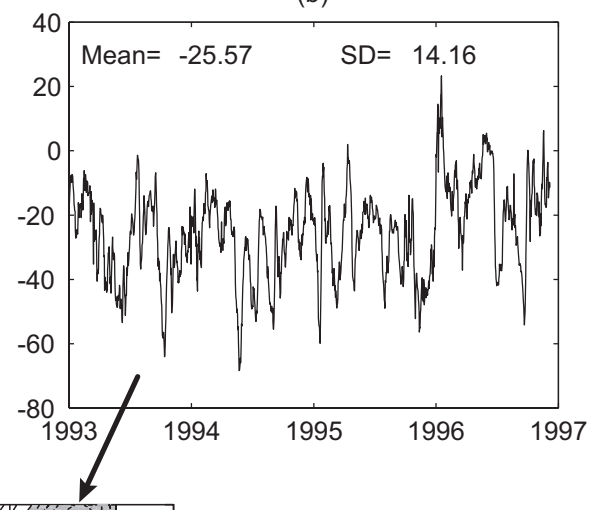


TABLE I

COMPARISONS BETWEEN MODEL AND OBSERVED FIELDS

\begin{tabular}{llll}
\hline Property & Model & Observed & References \\
\hline Transports (Sv) & & & \\
YC total mean transport & 25.3 & $25,23.8,28$ & {$[2],[3],[4]$} \\
Transport range & $16-32$ & $20-31,15-33$ & {$[2],[3]$} \\
Mean inflow transport & 33.3 & 33 & {$[2]$} \\
Mean outflow transport & 8 & 8 & {$[2]$} \\
Mean Core Velocity (m/s) & & & \\
Surface-western inflow & 1.5 & 1.3 & {$[2],[3]$} \\
Surface-eastern outflow & 0.25 & 0.15 & {$[2],[3]$} \\
Deep-western outflow & 0.17 & $0.2,0.1$ & {$[2],[3]$} \\
Deep-eastern outflow & 0.09 & 0.05 & {$[3]$} \\
\hline
\end{tabular}

Table I summarizes the main characteristics of the YC flow and compares the model results to published observations. The comparison shows good agreement between the model and observations in the mean and the range of the $\mathrm{YC}$ transport, as well as in the speed of velocities in the various cores shown in Fig. 2.

\section{B. Loop Current Variations and Yucatan Channel Transport}

As suggested by previous studies (see the introduction), variations in the extension of the LC may relate to variations in the YC transport. Moreover, variations in the LC results in the shedding of eddies at irregular intervals; those eddies then propagate westward across the GOM. The model, when driven by realistic high frequency winds, does shed eddies at irregular intervals of 4-12 months ([12]) in agreement with the observed eddy shedding frequencies in [13]. However, analysis of model results by [10] could not find significant correlations between eddy shedding in the GOM and transport variations in the YC.

We divide the total transport into three components: (a) the total inflow into the GOM (which is dominated by the surface-western inflow of Fig. 2a), (b) the top outflow above $800 \mathrm{~m}$ (which is dominated by the surface-eastern outflow of Fig. 2b), and (c) the deep outflow below $800 \mathrm{~m}$ (which is the sum of the two deep outflow cores of Fig. 2c and 2d). As an indicator for variations in the extension of the LC, we calculate the area averaged sea surface height over the rectangular shown in Fig. 1. When the LC grows, it occupies larger portion of this region and the mean elevation is larger (surface elevation south of the LC is higher than north of the LC). Fig. 3 shows how the LC extension relates to the inflow transport. If all daily values over the four-year period are included (small dots in Fig. 3), the model output does not have any significant correlation between the inflow transport and the LC extension. However, the correlation between the inflow transport and the LC extension is significant (correlation coefficient $R=0.7$ ) when only periods within 15 days before and 15 days after eddy shedding events are taken into account (filled circled in Fig. 3). This result can be explained as follows. During an eddy shedding event an increase in the inflow transport results in an increase in the LC area, as expected, but during other periods the increase in the inflow transport is compensated by an increase in the return flow along the eastern side of the Channel, as shown in [12], without causing changes to the volume of the LC.

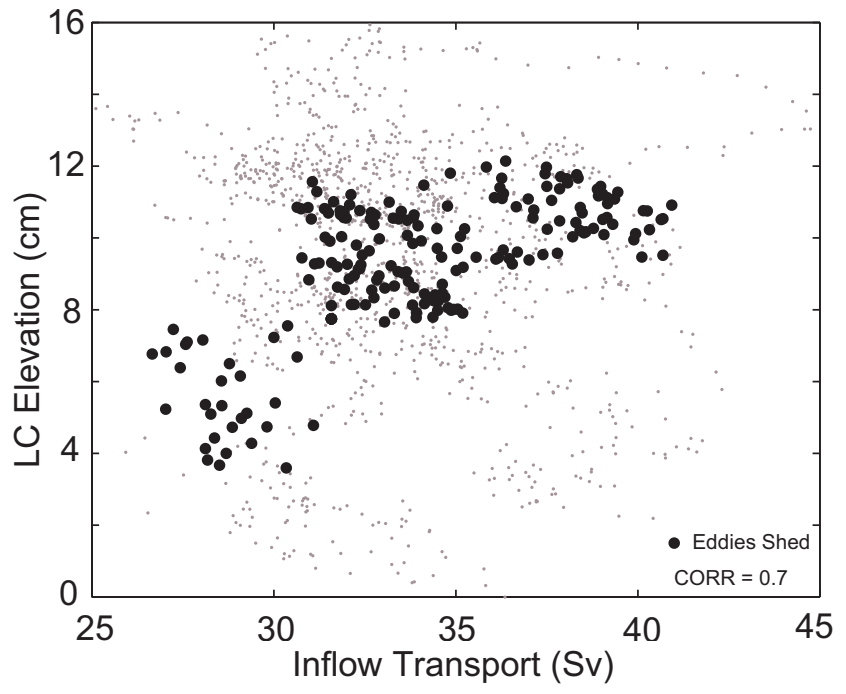

Fig. 3. Distribution of the daily inflow transport in the $\mathrm{YC}$ versus the area averaged LC elevation. Filled circles indicate periods within \pm 15 days of eddy shedding events. Seven eddies were shed from the LC into the GOM during the four-year simulation. Correlation coefficient was calculated only for the shedding periods.

The relation between the LC extension and the top and deep outflow transports are shown in Fig. 4. Note that the upper and deep outflows are not correlated with each other, when one is large the other one is usually small. The correlation between the inflow transport in Fig. 3 and the upper outflow is significant $(R>0.4)$, indicating that the inflow and outflow near the surface are at times compensating each other. When the outflow transports (either at the top or bottom) are large, large expansions in the LC area (circles and squares in Fig. 4) are often found.

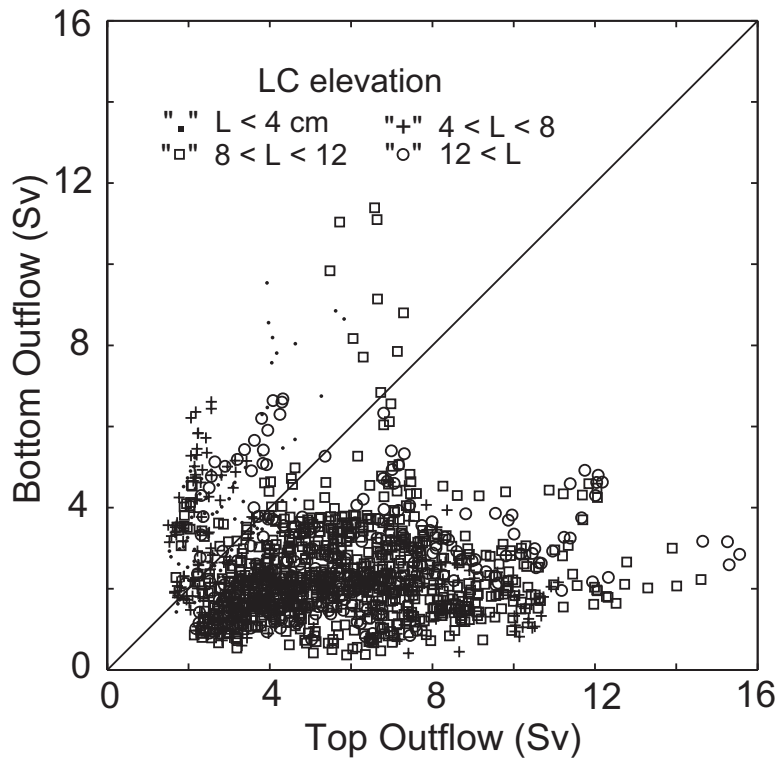

Fig. 4. Distribution of LC elevation as a function of top (x-axis) and deep (yaxis) outflow transports. The symbols represent different ranges in the LC extension area. 
As hypothesized in [1] and shown in [3], the deep return transport is expected to correlate with changes in the LC extension (not with the area averaged elevation $L$ itself, but with its derivative). Therefore, we calculate the daily change in the LC elevation, i.e., the derivative $\Delta L / \Delta t$; the distribution of this derivative as a function of the deep outflow is shown in Fig. 5. The data used to produce Fig. 5 have been smoothed since derivatives are noisy. We note first that there is a significant correlation $(R=0.4)$ between changes in the $\mathrm{LC}$ area and the deep outflow below $800 \mathrm{~m}$, so that increase in the deep southward outflow is an indication of growing LC, as proposed in [1]. Also shown in Fig. 5 are three examples of the changes that occur while eddies are shed. Other eddy shedding events show similar behavior. Before an eddy is shed there is an increase in the growing of the LC, and the eddy is shed from the LC just after the growing reaches its peak and starts to decrease. The return deep flow increases by about $0.1 \mathrm{~Sv} /$ day during the period before an eddy is shed, and then, often abruptly, stops growing, after the eddy is shed. The changes in the deep outflow are consistent with previous studies ([1], [3], [8]) suggesting that increasing/ decreasing in upper inflow to support growing/ receding of the LC is balanced by variations in the deep outflows. However, our results here further show the relation of the LC growth to the timing of eddy shedding events. Fig. 5 also suggests that in some cases eddy shedding events may be predicted days in advance, from the growing rate of the LC or from changes in the deep return transport.

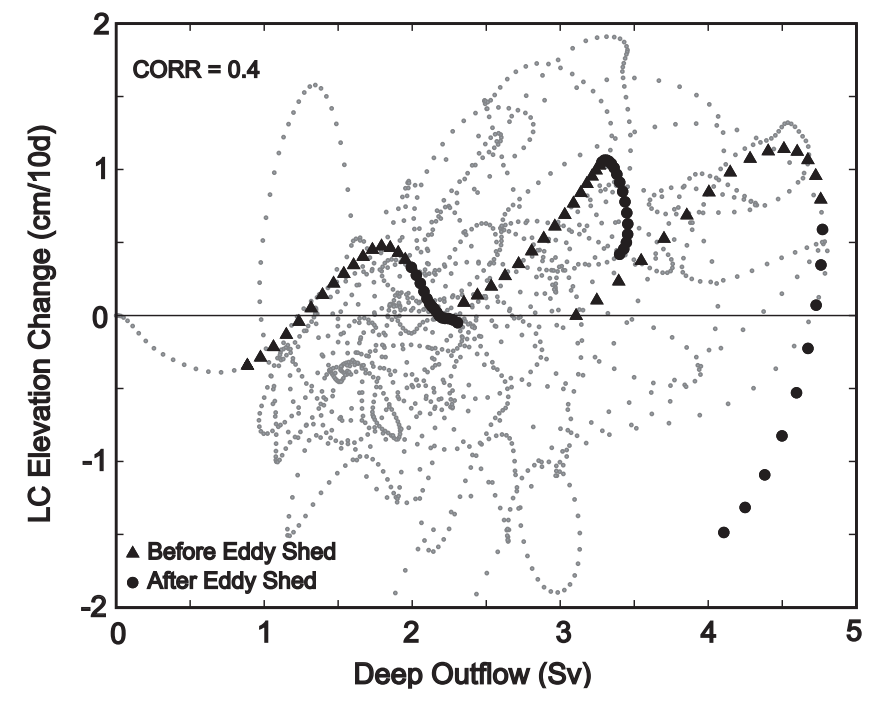

Fig. 5. The changes in the LC extension calculated from the changes in the area averaged elevation (expressed in units of $\mathrm{cm}$ change per 10 days) as a function of the deep outflow transport. Larger values in the $\mathrm{x}$-axis represent larger southward deep transports. Positive values represent growing LC, while negative values represent receding LC. Three periods when LC eddies are shed into the GOM are highlighted by triangles ( 15 days before an eddy is shed) and by circles (15 days after an eddy is shed).

\section{CONCLUSIONS}

Results obtained from a high resolution Princeton Ocean Model application for the western North Atlantic Ocean and driven by realistic winds have been analyzed. Several recent studies investigate different dynamical aspects of the model simulations, such as topographic Rossby waves ([6]), surface currents in the northeastern GOM ([11]), and the dominant modes of variability in the YC ([12]). In this paper we only focus on the spatial structure of the flow field across the YC and its relation to variations in the LC. In light of recent observations, reported in [2] and [3], the spatial structure of velocities and the variations in transport across the Channel may be quite different than previously thought. For example, the mean transport obtained from those observations is smaller by about $4 \mathrm{~Sv}$ than previous estimates of $28 \mathrm{~Sv}$ ([4]), and the range of transport variations is larger than expected. The new measurements also found strong return flows near the surface at the eastern side of the $\mathrm{YC}$ and at $\sim 1500 \mathrm{~m}$ depth on the eastern and western slopes, but not at the center of the channel as expected in [1]. This spatial structure of the flow field in the model (Fig. 2), as well as the transports and mean velocities at the various cores are all in good agreement with the new observations (Table I).

Time series of velocities show high frequency (mostly wind-driven) fluctuations as well as low frequency oscillations with periods of several months associated with transport variations and meandering of the LC (see [12] for more detail). Here we test the hypothesis that variations in the deep outflow are correlated with variations in the extension of the LC, as they balance the excess inflow needed to support the changes in the volume of the LC. The model results agree with [3] in this respect, but also show a more complex relation between the various transports and variations in the LC extension. We expected the inflow transport to correlate with the area occupied by the LC, however, such a relation exists only during periods near eddy shedding events. At other times the excess inflow is balanced by excess surface outflow without a net contribution to the growth of the LC. The transport of the deep outflow below $800 \mathrm{~m}$ was found to correlate with changes in the area of the $\mathrm{LC}$, as expected. Moreover, the timing of eddy shedding events seems to relate to the growing rate of the LC (Fig. 5). Before an eddy is shed the LC growing rate and the deep outflow increase, while after the separation of the eddy from the LC, both seem to decrease.

\section{Acknowledgments}

We thank the Deepwater Physical Oceanography Program managers of the Mineral Management Service, and the Ocean Modeling and Prediction Program managers of the Office of Naval Research for their support. T. E. thanks W. Sturges (FSU) for his support and advice. 
[1] G. A. Maul, D. A. Mayer, and S. R. Baig, "Comparisons between a continuous 3-year current-meter observation at the sill of the Yucatan Strait, satellite measurements of Gulf Loop Current area, and regional sea level", $J$. Geophys. Res., vol. 90, pp. 9089-9096, 1985.

[2] J. Ochoa, J. Sheinbaum, A. Baden, J. Candela, and D. Wilson, "Geostrophy via Potential vorticity inversion in the Yucatan Channel", J. Mar. Res., vol. 59, pp. 725$747,2001$.

[3] J. Sheinbaum, J. Candela, A. Badan, and J. Ochoa, "Flow structure and transports in the Yucatan Channel", Geophys. Res. Let., vol. 29, pp. 10.1-10.4, 2002.

[4] W. J. Schmitz Jr. and M. S. McCartney, "On the North Atlantic circulation”, Rev. Geophys., vol. 31, pp. 29-49, 1993.

[5] A. F. Blumberg and G. L. Mellor, "A description of a three-dimensional coastal ocean circulation model", Three-Dimensional Coastal ocean Models, Coastal Estuarine Stud., vol. 4, edited by N. S. Heaps, pp.. 1-16, AGU, Washington, DC., 1987.

[6] L.-Y. Oey and H.-C. Lee, "Deep eddy energy and topographic Rossby waves in the Gulf of Mexico", $J$. Phys. Oceanogr., In Press, 2002.

[7] L.-Y. Oey, H.-C. Lee, and T. Ezer, "An embedded circulation model of the Gulf of Mexico Part I: Descriptions and experiments using ECMWF winds and satellite data", unpublished, 2002.
[8] L.-Y. Oey, "Simulation of mesoscale variability in the Gulf of Mexico: Sensitivity studies, comparison with observations, and trapped wave propagation", J. Phys. Oceanogr., vol. 26, pp. 145-175, 1996.

[9] H. E. Hurlburt and J. D. Thompson, "A numerical study of Loop Current intrusions and eddy shedding", J. Phys. Oceanogr., vol. 10, pp. 1611-1651, 1980.

[10] S. J. Murphy, H. E. Hurlburt, and J. J. O'Brien, “The connectivity of eddy variability in the Caribbean Sea, the Gulf of Mexico, and the Atlantic Ocean", J. Geophys. Res., vol. 104, pp. 1431-1453, 1999.

[11]D.-P. Wang, L.-Y. Oey, T. Ezer, and P. Hamilton, "The near-surface currents in DeSoto Canyon (1997-1999): Observations, satellite data, and comparison with model simulations", unpublished, 2002.

[12] T. Ezer, L.-Y. Oey, W. Sturges, and H.-C. Lee, "The variability of currents in the Yucatan Channel: Analysis of results from a numerical ocean model”, unpublished, 2002.

[13] W. Sturges and R. Leben, "Frequency of ring separations from the Loop Current In the Gulf of Mexico: A revised estimate", J. Phys. Oceanogr., vol. 30, pp. 1814-1818, 2000. 